\title{
Our Vision
}

\section{Viviana Siddhi*}

Slovenian-Born Artist, NGO Mandala Transformation, USA

*Corresponding author: Viviana Siddhi, Slovenian-Born Artist with American Citizenship, NGO Mandala Transformation, Inc., California, USA.

\section{Short Communication}

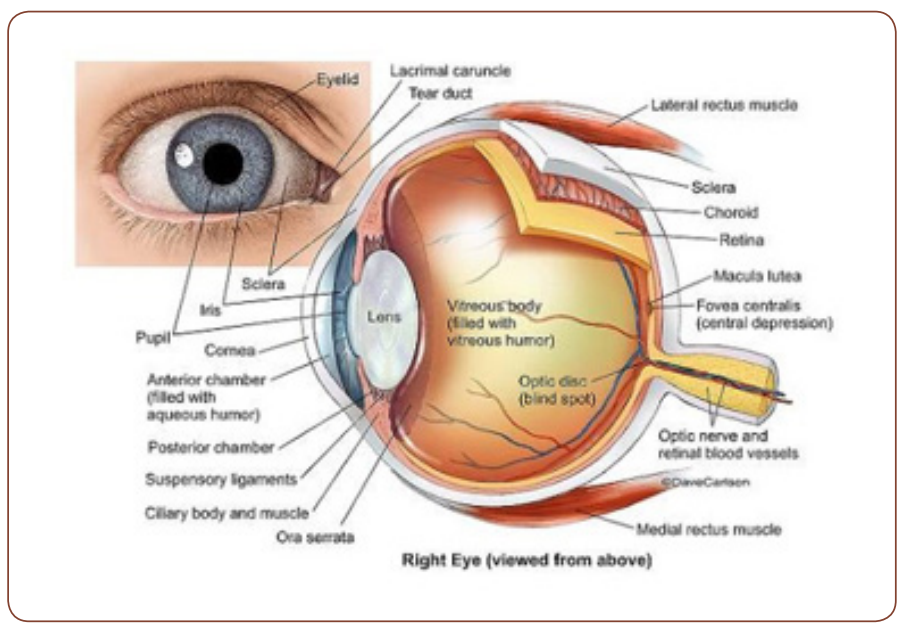

In just the last 100 years, eyesight in developed countries has become significantly worse.

Your eyes are your window to the world. Without your eyes you wouldn't be able to see the sun rise in the morning or set at night or see the happy faces of your friends and family. Your eyes allow you to experience the world in which you live, that's why you need to do everything you can to keep your vision perfect.

How exactly do your eyes see everything? They are about 1 inch apart and made up of tiny living cells. They contain $70 \%$ of the sense receptors in your body. The eye is made up of several components - the cornea, pupil, iris, lens, sclera and retina. These components work together to capture an image and send it to the brain through the optic nerve. When we look at an object, light is reflected off the object and enters through the eye. The retina creates a focused, but upside-down image of the object. Optic nerve is located at the back of the eye. It transmits the electrical impulses from the retina to the brain. Ultimately it tells our brain what we are looking at. The brain then restores the image back to its correct direction while also creating the object to be three-dimensional.

"Eyeglasses represent the traditional way of correcting vision, whereas contact lenses are a newer approach. Lasik surgery can be performed to change the shape of the cornea of the eye. Eyeglass or spectacle correction has been used for several centuries. Lenses are ground in such a way as to neutralize the refractive error found on examination. Myopia, hyperopia, and astigmatism can generally be corrected [1]."

"Lasik is an outpatient procedure, performed under local anesthesia. The excimer laser is controlled by a computer that has been programmed to create an optical correction specifically for your eye.

As you recline under the laser instrument, your eye is anesthetized with drops and calculations are re-checked. A speculum holds your eyelids apart, and a suction ring is placed on the eye. A corneal flap is then created with a microkeratome, a specialized instrument that works like a tiny carpenter's plane. You won't feel any pain, but you may feel a pressure sensation from the suction ring and your vision may black out for a few seconds, until the ring is removed.

The corneal flap is lifted, exposing the tissue to be reshaped. A beam of intense laser light sweeps over the cornea for about 10 to 
60 seconds, depending on your refractive error. The laser reshapes the cornea by precisely vaporizing microscopically thin layers, not by burning it [2]."

Blaming genetics for your poor eyesight and claiming there's nothing you can do about it, is not true. Our vision is constantly changing. Our eyes feel tired after a long day of working at the computer. When we wake up in the morning it takes a while for your eyes to focus. Our eyes require time to "adjust".

"Reading in dim light will ruin your eyes, right? Wrong - that's a myth, as is the idea that sitting too close to the TV screen or reading by flashlight will harm your vision. These habits won't do permanent damage to your eyes. But any close-up work, like reading, computer work or crafts, can result in eyestrain. Your eyes may feel dry, irritated, sore or tired. You may have blurred vision, a headache or a sore neck [3]."

\section{Why your vision gets bad?}

Humans have evolved to have excellent vision. Our ancestors depended upon good vision for survival. Your vision should allow you to participate effectively in hunting for wild food resources. Men, the primary hunters, required the ability to see clearly across a vast field to bag the dinner. Women as primary foragers benefited from strong visual sharpness up close as they located. This is the reason why men tend to have better distance vision and women have better near vision.

"According to Dr.Loren Cordain, vision impairments are virtually nonexistent. Statistics in these traditional groups for myopia settle out at 0 to $3 \%$ and consist of almost exclusively mild cases. If we look at statistics from modern societies, we find a much different picture. The numbers for myopia, for example, have skyrocketed in the last thirty years. In the U.S. the prevalence of myopia is $42 \%$ [4]."

Diet plays a significant role in the quality of your eyesight. In particularly, processed foods and other toxins. Many of the toxins we are exposed to everyday, can impair our vision.

Your eyes are basically made up of a lot of tiny little cells. If there are too many toxins around these cells, they don't function properly. As a result, your vision begins to worsen. In our modern world we are bombarded with thousands of toxic chemicals. Also lack in key eye nutrients is leading cause of eye problems.

"Eyestrain occurs when your eyes tire from intense use, such as driving a car or reading for extended periods, exposure to bright lights or glare, or spending long hours in front of computer.

\section{Eyestrain Home Remedies}

- Direct your light. For close-up work, use light that's directed on what you're doing. When reading, position the light source behind you and direct the light onto the page. When reading at a desk, use a shaded light positioned in front of you.
- $\quad$ Take frequent eye breaks throughout the day. Try to stand up and move around at least once every hour or so.

- $\quad$ Blink often. This helps to refresh and lubricate your eyes. Because many people blink less than normal when working at a computer, dry eyes often result from prolonged computer use [5]."

Make sure to remove your glasses or contact lenses during exercises.

We don't use our eyes the way we used to from young age. Today, we spend almost all our time staring at a TV or a computer screen. As a result, millions of adults who should have healthy vision now have nearsightedness. When was the last time you went out for a walk and actually looked at the horizon line and used your long-range vision? Poor vision has almost nothing to do with genetics. We just aren't using our eyes the way they're designed to be used. It's basically a matter of "Use-it or Lose-it". The real reason your eyesight is poor is because of poor eating habits and toxins, malnourishment and just not using your eye muscles enough.

\section{What to do to Help you Get the Best Eyesight you've} Ever Had?

1. Optimize your diet and cleanse: eat a nutrient rich diet, cleanse your body and eyes from chemicals and pollutants.

2. Nourish your eyes: eat nutrition that is needed for eyes, add compounds that reverse and repair damaged eye cells. It's very important that you get large amounts of organic fresh, raw vegetables in your diet, every day.

3. Eye strengthening exercises: follow daily eye exercises, cure eye condition with a specific eye exercise routine.

"Studies have shown that oxygen improves strength and energy, reduces stress on the heart and even increases mental focus and concentration [6]."

Healthy blood cells are separated and strong so they can get through narrow spaces and keep your eyes and body oxygenated. When your body is too acidic, your blood starts to clump together causing all sorts of problems including vision problems. The good thing is that it's easy to fix. You just have to adjust your diet to include more foods that are alkaline and fewer foods that are acidic.

Alkaline food: apples, water, olives, tomatoes, celery, pears, grapes, radish, bananas, peaches, corn, mushrooms, apricot, sweet potatoes, soybeans, grapefruit, avocados, peas, green tea, kiwi, melons, beets, tangerines, figs, spinach, broccoli, cucumbers, carrots, cauliflower, lemons, cabbage, onion, asparagus, seaweed, kale.

Specific nutrients for your eyes are beta carotene, vitamin C, vitamin E, copper, zinc, lutein, bilberry, golden seal root, marshmallow root, eyebright extract, cayenne pepper. 
"Bilberry (Vaccinium myrtillus) acts as a potent antioxidant, enhances blood circulation, has anti-inflammatory properties, and enhances the regeneration of rhodopsin (visual purple) in the retina. It has been shown to be completely nontoxic, with no side effects and no contraindications. Some of the uses of bilberry for the eye include improving night vision, cataracts, nearsightedness, diabetic retinopathy, eyestrain, macular degeneration, and glaucoma [7]."

We all have a bad habit we need to break. Rubbing your eyes can break tiny blood vessels under the skin's surface. If you don't drink 8 glasses of water per day you become dehydrated, you are draining your eyes out of the moisture they need to create enough tears to stay healthy. Your body is made up of $70 \%$ water. Symptoms associated with dehydration in the eyes are redness, puffy eyelids and dryness. Eyes needs oxygen. We should always take a break and not wear contacts or eyeglasses. Give your eyes time to breath. Use a low watt reading light for reading.

If you do eye exercises every day, you can gradually improve any common vision problem. Examples for eye exercises: change focus every two seconds, breathing slowly and deeply, blink, clock rotations, slowly roll your eyes in a complete circle, squeeze blinking, palming, hydrotherapy, acupressure. Alkalizing the body helps tremendously. Amazing results are produced by retraining oneself to see by using neck muscles rather than the eye muscles.

"Reflexologists use pressure applied to reflex areas on the sole of the foot to communicate with corresponding parts of the body via the central nervous system, helping them to function as well as they can. Reflex areas on the feet form "maps" that approximate to the body's anatomy, with areas on the toes and heels, for example, reflecting the head and lower back respectively. Some reflex areas overlap, indicated by broken lines [8]."

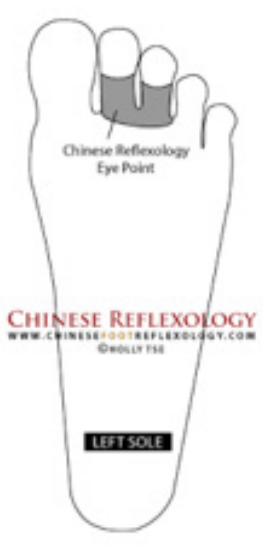

The mind is a powerful thing to waste. And wherever the mind goes, the body will follow. Harnessing the power of our mind is so powerful and yet very few of us actually use its power to shape our self-image and to create perfect health.
In the past decade or so, hundreds of studies have been conducted that demonstrate the powerful connection between mind and body. While Napoleon Hill figured it out many years ago, many scientists now believe that what you think about actually shapes your life.

Scientific research actually shows that your mind affects the cells of your body and even your DNA. So, if your self-image is someone with poor vision, your cells will actually force you to see poorly. Your self-image has powerful effect on your body. In order to be glasses free, you need to change your self-image. We all have an image of ourselves in our subconscious mind. Your current selfimage was built and shaped by interpretations and evaluations you place on past experiences.

For example, let's just say that at some time in your past, your eye doctor told you your vision was getting worse, or that you need to start wear glasses. And regardless of whether you noticed anything wrong with your vision, you may have started thinking there was. You may have imagined yourself being unable to see clearly. This may be something there was. You may have imagined yourself being unable to see clearly. This may be something that you consciously played out in your mind. It isn't the actual experience that shapes your self-image but the act of imagining yourself in a certain way that affects your self-image. Your mind and body react to your internal self-image. So, if your self-image is that of a person with poor vision, your body will do everything that it can to make that true.

Begin by imagining yourself completely free of glasses or contact lenses. Free of blurred vision. Imagine going to your optometrist and to their amazement, you're vision actually reversed course and now you have perfect $20 / 20$ vision.

\section{Acknowledgement}

None.

\section{Conflict of Interest}

Author declares no conflict interest.

\section{References}

1. Jay B Lavine (2001) The Eye Care Sourcebook. USA, p. 40.

2. Melvin L Rubin, Lawrence A Winograd (2002) Taking Care of Your Eyes. USA, P. 88

3. Helmut Buettner (2002) Mayo Clinic on Vision and Eye Health. USA, p.58.

4. (2017) Quantum Vision System. QuantumVisionSys.com, USA, p.18.

5. Brent A Bauer, Cindy A Kermott, Martha P Millman (2017) The Integrative Guide to Good Health. USA, p. 291.

6. Neil Schachter (2003) Life and Breath. USA, p. 207.

7. Jeffrey Anshel (1999) Smart Medicine for Your Eyes. USA, p. 49.

8. Barbara, Kevin Kunz (2009) Complete Reflexology for Life. India, p. 26. 